\title{
Necroinflammation emerges as a key regulator of hematopoiesis in health and disease
}

\author{
Philipp J. Jost $\mathbb{B}^{1,2} \cdot$ Ulrike Höckendorf ${ }^{1}$
}

Received: 15 May 2018 / Revised: 5 August 2018 / Accepted: 10 August 2018

(c) ADMC Associazione Differenziamento e Morte Cellulare 2018

\begin{abstract}
The hematopoietic system represents an organ system with an exceptional capacity for the production of mature blood cells from a small and mostly quiescent pool of hematopoietic stem cells (HSCs). This extraordinary capacity includes selfrenewal but also the propensity to rapidly respond to extrinsic needs, such as acute infections, severe inflammation, and wound healing. In recent years, it became clear that inflammatory signals such as cytokines, chemokine and danger signals from pathogens (PAMPs) or dying cells (DAMPs) impact on HSCs, shaping their proliferation status, lineage bias, and repopulating ability and subsequently increasing the output of mature effector cells. However, inflammatory danger signals negatively impact on the capacity of HSCs to self-renew and to maintain their stem cell capabilities. This is evidenced in conditions of chronic inflammation where bone marrow failure may originate from HSC exhaustion. Even in hematopoietic cancers, inflammatory signals shape the phenotype of the malignant clone as exemplified by necrosome-dependent inflammation elicited during malignant transformation in acute myeloid leukemia. Accordingly, understanding the contribution of inflammatory signals, and specifically necroinflammation, to HSC integrity, HSC long-term functionality, and malignant transformation has attracted substantial research and clinical interest. In this review, we highlight recent developments and open questions at the interplay between inflammation, regulated necrosis, and HSC biology in the context of blood cell development, acute and chronic inflammation, and hematopoietic cancer.
\end{abstract}

\section{Facts}

- Inflammatory signals directly and indirectly impact on hematopoietic stem cell (HSC) biology.

- Pyroptotic and necroptotic cell death kill normal hematopoietic stem or progenitor cells (HSPCs) and leukemic cells.
- Excess inflammatory signaling inhibits or exhausts hematopoiesis, contributes to HSPC dysfunction, and potentiates hematopoietic pathologies.

- Inflammatory signals block normal HSC growth yet promote survival and proliferation of certain neoplastic cells as evidenced in myelodysplastic syndromes (MDSs), myeloproliferative neoplasms (MPNs), and Fanconi anemia.

\section{Open questions}

- How does chronic inflammation induce exhaustion of HSCs and does that contribute to leukemic transformation?

Philipp J. Jost

philipp.jost@tum.de

1 Medical Department III of Hematology and Oncology, Klinikum Rechts der Isar, Technische Universität München, 81675 München, Germany

2 German Consortium for Translational Cancer Research (DKTK), Partner Site Munich, German Cancer Research Center (DKFZ), Heidelberg, Germany
- Which cells induce the inflammatory signals that drive the development and progression of hematologic malignancies and what are the deregulations underlying aberrant cytokine production?

- What are the specific damage-associated molecular patterns (DAMPs) that drive inflammation under conditions of infection or malignancy? 


\section{Necroinflammation}

Necroinflammation is defined as the immune response to regulated or non-regulated necrosis in a living organism. Regulated necrosis is executed as a controlled process through defined signaling pathways such as necroptosis, ferroptosis, and pyroptosis or, alternatively, may proceed in a non-regulated fashion as consequence of traumatic injuries [1]. As the consequence of necrosis, however, all necrotic cells release their intracellular content as danger molecules from dying cells (also termed damageassociated molecular patterns (DAMPs)), such as ATP, heat shock proteins (HSPs), high-mobility group box 1 (HMGB1), mtDNA or uric acid among the interleukins such as IL- $1 \alpha$, IL-18, IL-1 $\beta$, IL-33, among others. These molecular danger signals trigger a robust inflammatory immune response that further promotes immunity-related cell death, thereby constituting a feed-forward loop [2]. Moreover, recent data suggest that each particular pathway of cell death has specific signatures that actively fine-tune the immune response by the expression and/or maturation of either pro- or anti-inflammatory cytokines and chemokines [1]. This subject of necroinflammation is elucidated systematically in several current reviews $[1,3,4]$.

Despite a wealth of data on the role of apoptotic cell death in the hematopoietic system, the characterization of regulated necrosis and subsequent necroinflammation in hematopoiesis remains incomplete. Research on necroinflammation in the hematopoietic system has mainly focused on necroptosis and pyroptosis with only little data available on ferroptosis or alternative regulated forms of necrosis. A wide range of inflammatory stimuli trigger necroptosis, including tumor necrosis factor (TNF) superfamily members such as TNF, Fas (CD95), and TNF-related apoptosisinducing ligand (TRAIL) [5]. Moreover, interferons (IFNs) [6], ligands of the Toll-like receptor (TLR) pathways [7], and nucleic acid-activated pathways [8] also induce necrosome formation. Moreover, several stresses can promote necroptotic cell death including tissue damage as observed in ischemia-reperfusion injury, production of reactive oxygen species, chemotherapeutics, and glutamate or calcium overload [9].

TNF represents the best-studied inducer of necroptosis under certain cellular conditions of stress. In healthy cells, TNF mostly induces survival and/or inflammatory response genes, however, under conditions of cellular stress resulting in the depletion of certain signaling compounds, TNF induces different forms of cell death including necroptosis. This depends, at least in part, on the sequential formation of different TNF receptor signaling complexes upon binding of TNF to TNFR1 [10], resulting in two very different outcomes: (i) transcriptional responses based on the activation of nuclear factor- $\mathrm{KB}(\mathrm{NF}-\kappa \mathrm{B})$ and mitogenactivated protein kinases (MAPKs) c-Jun N-terminal kinases (JNK) and p38; (ii) propagation of cell death via an apoptosis or necroptosis route.

The binding of TNF to the TNF receptor 1 (TNFR1) results in the oligomerization of the receptor and subsequent intracellular formation of a signaling complex termed the TNFR1 signaling complex (TNF-RSC). Initiated by recruitment of the death domain (DD)-containing proteins Tumor necrosis factor receptor type 1-associated death domain protein (TRADD) and Receptor-interacting serine/ threonine-protein kinase 1 (RIPK1) to the DD of TNFR1, the TNF-RSC is referred to as complex I. Physiologic complex formation then requires TRADD-dependent recruitment of TRAF2 [10]. This platform subsequently serves to recruit the cellular inhibitors of apoptosis proteins (cIAP)1 and cIAP2. Following their recruitment, cIAPs attach K63-linked ubiquitin chains on various TNF-RSC components, including RIPK1, which allows for activation of NF-kB and MAPKs and subsequent transcriptional activation of proinflammatory genes. Subsequently, linear ubiquitin chain assembly complex (LUBAC) is recruited to the complex. LUBAC contains the protein subunits HOIL-1, SHARPIN, and HOIP and attaches linear ubiquitin chains (M1-linked) on components such as RIPK1 and nuclear factor- $\mathrm{KB}$ essential modulator (NEMO). Accordingly, the composition and functionality of complex $\mathrm{I}$ is defined to a large degree by the correct positioning and timing of ubiquitin chains onto the proteins within the complex, resulting in the recruitment of NEMO plus IKB kinase (IKK) and TAK1-Binding Protein 1 (TAB) plus TAK, allowing for the activation of NF- $\mathrm{KB}$ and MAPKs [11].

Aberrant IAP or LUBAC activity, or RIPK1 deubiquitylation mediated by Lysine 63 Deubiquitinase (CYLD), results in defective recruitment of various TNFRSC components and complex destabilization [11, 12]. This shifts the signaling toward enhanced formation of an alternative, also termed secondary, death-inducing complex II and the subsequent recruitment of Fas Associated Via Death Domain (FADD) and pro-Caspase-8 [10]. Caspase-8 stands at the cross-road of apoptotic and necroptotic cell death by either promoting conventional caspase-dependent cell death or, when insufficient Caspase8 activity is present, causing necroptotic cell death in cells proficient for RIPK3 and Mixed Lineage Kinase Domain Like Pseudokinase (MLKL). Here, activated RIPK1 promotes necroptosis by interacting with RIPK3, which in turn mediates the phosphorylation of the pseudokinase MLKL resulting in pore formation at the plasma membrane to promote cell lysis [13].

The molecular mechanisms controlling complex II formation are not entirely understood, but it is clear that RIPK1 has a central position in this process. This has been 
established by genetic models showing that loss of cIAPs, NEMO, TAK1, or LUBAC components sensitizes cells to TNF-mediated cell death in a RIPK1-dependent manner. Failed activation of NF- $\mathrm{KB}$ targets impacts on the composition of complex II, but additional effects mediated by transcription factors other than NF- $\mathrm{\kappa B}$ have been proposed [11]. RIPK1 ubiquitin modifications are critical components of the post-translational editing of this central player in necroptosis and inflammatory signaling, yet the events controlling de-ubiquitylation remain only partially understood. Whereas the deubiquitylase (DUB) CYLD is only partially required for necroptosis to occur, other DUBs such as OTULIN might provide overlapping functionality in TNF-dependent or TNF-independent signaling complexes [14]. Of note, loss of the ubiquitin signature on RIPK1 promotes but is not necessary for necroptosis to occur as aberrant ubiquitylation patterns of RIPK1 have also been detected in complex II. This suggests that the chain type or the branching pattern of ubiquitin chains on RIPK1 might define its role within the necrosome [15]. Additional insights into the posttranslational modification of RIPK1 will help to understand their contribution to the composition of signaling platforms containing RIPK1 either at the receptor level or as cytoplasmic protein complexes.

\section{Inflammatory roles of RIPK1 and RIPK3}

Several lines of evidence show that both RIPK1 but also RIPK3 promote inflammation independently of the inflammatory processes associated with cell death. These inflammatory responses are controlled, at least in part, by effector molecules such as ERK1 and ERK2 after recruitment to RIPK1/RIPK3 complexes [16] or by synthesis and release of inflammatory mediators such as TNF [17-19]. Moreover, several receptors such as TNFR1 primarily engage in proinflammatory gene transcription by activating NF-кB [20]. Besides, several groups including our own have shown that RIPK1 and RIPK3 promote the release of IL-1 $\beta$ from macrophages and dendritic cells in response to TLR4 or TNFR1 stimulation $[21,22]$. IL- $1 \beta$ is a potent inflammatory cytokine, also considered a DAMP, which requires de novo synthesis and subsequent processing by Caspase- 1 or, alternatively, Caspase-8 for activation [21]. RIPK3 promotes IL-1 $\beta$ processing mostly by the NLR Family Pyrin Domain Containing 3 (NLRP3)/Caspase-1 inflammasome complex or, to a smaller degree, by Caspase-8 [21-25]. In addition, RIPK1 and RIPK3, but not MLKL, control the production of proinflammatory cytokines such as IL-6 and TNF in myeloid cells depending on the amplification of the intrinsic TNF/TNFR1 signaling axis [26]. A specifically intriguing way of promoting proinflammatory responses in myeloid cells is the temporal delay in necroptosis execution in cells undergoing death signaling. This process extends the time for cell-intrinsic NF- $\mathrm{\kappa B}$-dependent transcriptional responses of proinflammatory mediators before cells eventually lyse. Hence, this process facilitates the cross-priming of $\mathrm{T}$ lymphocytes from dendritic cells thereby substantially increasing the inflammatory output of myeloid cells [27]. Together, these data show that RIPK1 and RIPK3 promote inflammation by multiple means and that NF- $\mathrm{kB}$-mediated responses and regulated necrosis seem to synergize in maximizing the inflammatory responses from myeloid cells in response to stress signals.

\section{Inflammatory signals regulate hematopoietic stem cell fate and blood output}

As evidenced by the critical function of the hematopoietic system in inflammation, immunity, and tissue repair, this organ system is highly responsive to inflammatory signals released from pathogens or damaged tissue [28]. An increasing number of reports using murine and zebrafish models, as well as single-cell analyses delineated the chemokines and cytokines that directly influence the proliferative capacity, differentiation, and self-renewal of hematopoietic stem cells (HSCs).

HSCs represent a rare, multipotent cell type that is able to generate all mature hematopoietic cell types in the peripheral blood via progenitor and precursor stages (Fig. 1). Healthy hematopoietic stem or progenitor cells (HSPCs) are capable of sensing a plethora of inflammatory stimuli including chemokines and cytokines, DAMPs and TLR ligands $[29,30]$. The HSPC compartment responds to these stimuli during conditions of stress by proliferation and the release of cytokines that result in a strongly intensified hematopoiesis (also termed emergency granulo-/myelopoiesis), which provides sufficient numbers of myeloid immune cells to the sites of infection [31-35]. It is well established that inflammatory signals such as IFNs, TNF, IL-1, or DAMPs impact both negatively or positively on the cellular output of the healthy bone marrow (BM) and even of the cellular integrity of leukemic cells.

Aside from canonical effects on immune effector cells, these danger signals also directly affect HSPC biology. Indeed, proinflammatory cytokines seem to be critical for the maintenance of the correct cell numbers, proliferative state and differentiation level of HSPCs at steady-state or, alternative, during stress responses (Fig. 2). Moreover, aberrant levels of these proinflammatory cytokines and the subsequent impact on primitive hematopoietic progenitor 


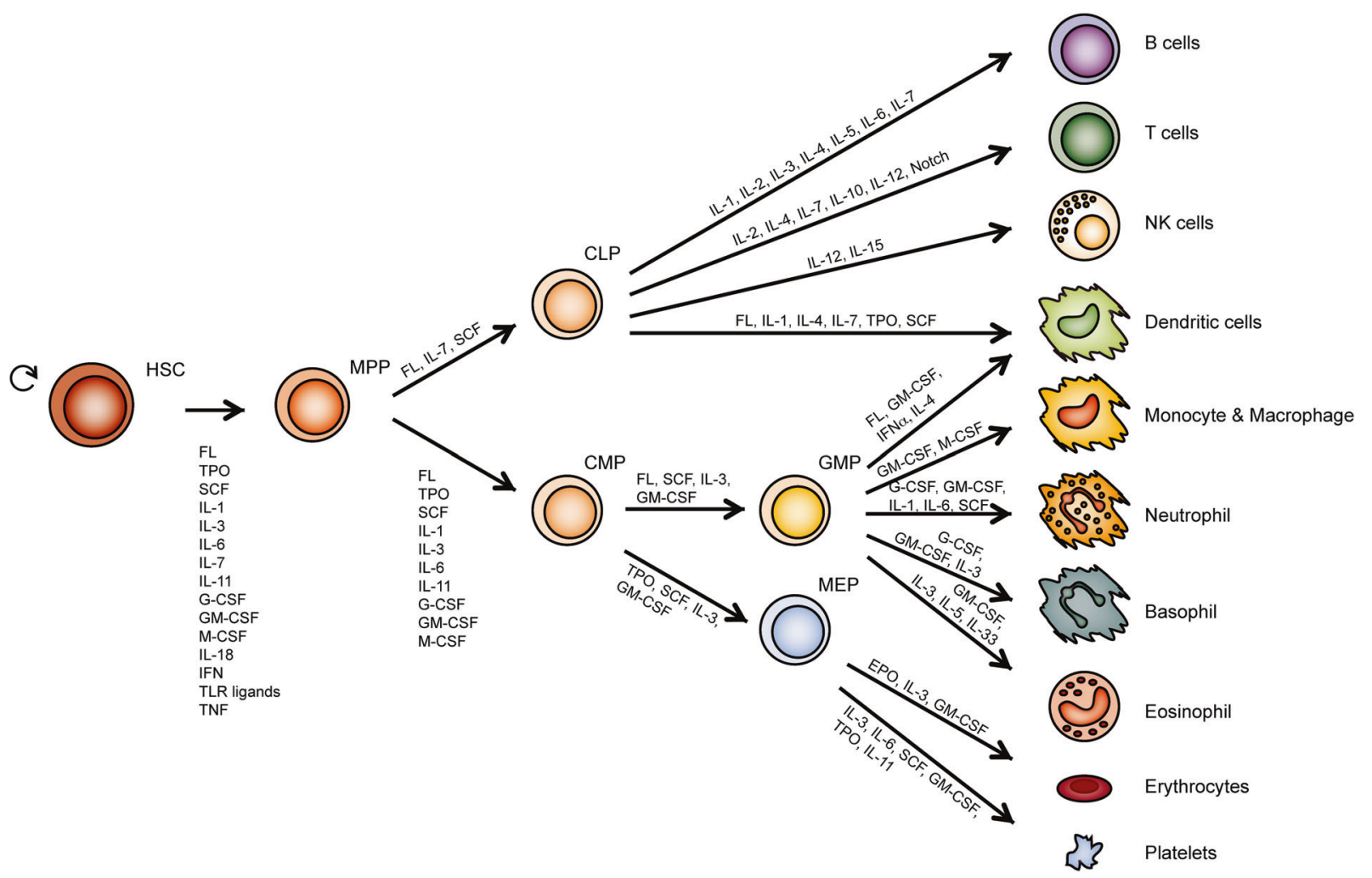

Fig. 1 The interaction of different cytokines coordinates hematopoiesis. Throughout the development of hematopoiesis, self-renewing multipotent stem cells (HSC) produce more committed progenitor cells. These cells form the foundation for the generation of mature blood cell lineages present in the peripheral blood. Classically, hematopoietic commitment is described to split between myeloid and lymphoid fate immediately downstream of multipotent progenitors (MPPs). This view, however, has been challenged by several recent reports demonstrating that lineage fates remain undecided over several early cell populations (data not shown). Shown here are cytokines and other inflammatory signals that positively control the self-renewal

populations likely foster hematological conditions such as cancer, BM failure (BMF) syndromes or even aging [30]. Thus, to identify how inflammation regulates HSC fate and shapes the blood system during development, aging, chronic inflammation, and hematological malignancy, it is critical to understanding the mechanistic base of these processes and the potential links between them.

\section{The role of (necro)inflammation in demand- adapted hematopoiesis}

At steady-state cell-intrinsic transcription factors, as well as epigenetic regulators [36] in combination with nichemediated signals maintain HSCs at a quiescent state [37, 38]. However, during conditions of infection, inflammatory signals rapidly drive HSCs out of quiescence and induce transient proliferation. In this setting, danger signals such as and differentiation of HSPCs. Interleukins (ILs) and colonystimulating factors (CSFs) coordinate to a large degree the proliferation and differentiation of HSPCs by controlling critical intracellular signaling pathways both at steady-state and during conditions of stress. The elements shown influence HSPC proliferative capacity, their ability for multipotency, and their commitment to specific lineages. MPP multipotent progenitor, CLP common lymphoid progenitor, CMP common myeloid progenitor, GMP granulocyte-macrophage progenitor, MEP megakaryocyte-erythrocyte progenitor, NK natural killer, FL FLT3 ligand, SCF stem cell factor, TPO thrombopoietin, EPO erythropoietin

interleukins play a critical role. IL-1 $\alpha$ and IL-1 $1 \beta$, the most commonly studied DAMPs of the necroptotic $[2,39]$ and pyroptotic cell death pathways [40,41], are potent inducers of IL-6 and granulocyte colony-stimulating factor (G-CSF), all of which induce HSC proliferation and promote rapid granulopoiesis [42-44]. However, the functional consequence of IL-1 $\beta$ signaling in hematopoiesis originating from different inflammasomes remains incompletely understood. Next to IL-1 $\beta$, Caspase-1 also processes IL-18 as a major proinflammatory cytokine, which induces IFN $\gamma$ to control the proliferation, self-renewal, and repopulating capacity of HSCs under conditions of infection [45, 46].

Moreover, during the process of regulated necrosis alternative interleukins such as IL-33 are released [32] and subsequently inducing the mobilization of HSPCs and promoting the production of IL-5, a strong trigger for eosinophilia [47-49]. IL-33 itself plays an integral part in coordinating immunity against helminths and it is involved 


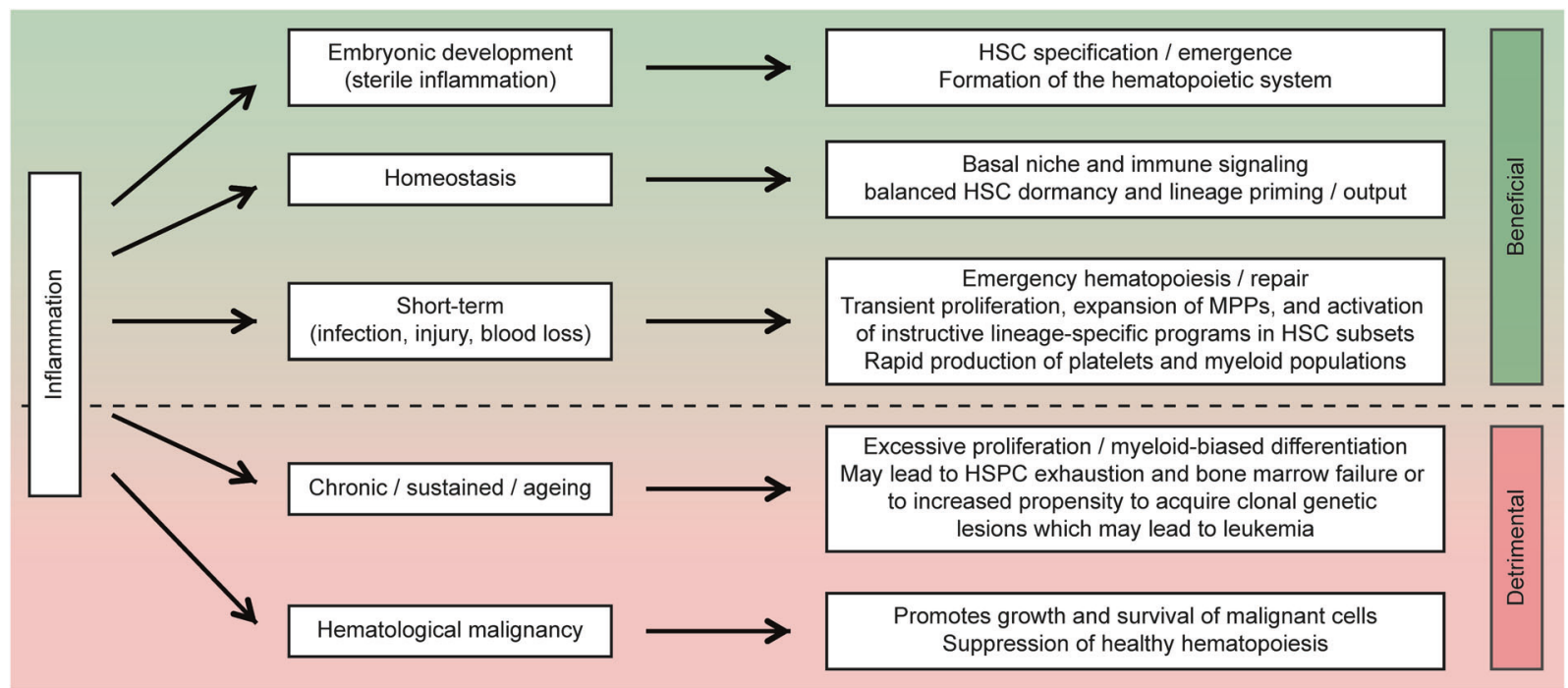

Fig. 2 The positive and negative effects of inflammation on bone marrow integrity and HSC function. Representation of selected effector processes activated by inflammation in the bone marrow and short description of their relevance in the bone marrow. Processes on the upper half of the circle (shown in green) represent beneficial mechanisms to control and maintain hematopoiesis under steady-state conditions or, alternatively, during acute stress responses. The bottom half of the circle (shown in red) shows aberrant and potentially harmful inflammatory processes in the bone marrow such as chronic inflammation, the process of ageing and malignancy. It remains a challenge to delineate the partnership and antagonism of inflammation and HSPC biology in developmental and disease contexts in allergy, where it promotes the induction of type-2 innate lymphoid cells (ILC2) [50].

IFNs represent another major class of inflammatory signals controlling HSCs [46, 51]. IFNs group into two separate classes: type I IFN, including IFN $\alpha$ and IFN $\beta$ binding the IFN $\alpha$ receptor, and the type II IFN $\gamma$ binding the IFN $\gamma$ receptor [52]. Murine models exposed to purified IFN $\alpha$ or poly(I:C) induce HSC proliferation [51, 53]. Accordingly, the IFN $\alpha$-dependent transcriptional regulator Irf2 repressing IFN $\alpha$ signaling prevents HSC exhaustion and induces HSC quiescence [53, 54]. Of note, IFN $\gamma$ has discrete effects on the differentiation of HSCs. Constant exposure to IFN $\gamma$ suppresses growth of HSPCs by inducing myeloid differentiation and apoptosis [55-60] and certain BMF syndromes such as acquired aplastic anemia potentially originated in an aberrantly elevated level of IFN $\gamma[61$, 62]. Conversely, recent publications showed that IFN $\gamma$, like type I IFNs, can also stimulate HSC self-renewal, repopulation, and proliferation under conditions of infectious stress, likely to maintain blood cell homeostasis over the course of infection [46, 63, 64]. Thus, it appears that the baseline IFN $\gamma$ tone regulates HSC activity. Although IFN $\gamma$ is key to stimulate emergency HSC proliferation, excessive signaling through this pathway might be detrimental to HSC function.

In analogy to IFN $\gamma$, studies of the specific hematopoietic actions of TNF have been conflicting. TNF blocks cellular growth and promotes apoptosis specifically of HSCs, which contrasts to most cell types in body [58, 64-69].
Interestingly, current data suggest that TNFR1 and TNFR2 differentially block HSCs; TNF mostly impacts on committed progenitor cells via TNFR1, whereas primitive hematopoietic progenitor cells receive signals from TNF signals via TNFR2 $[65,66,68]$. In contrast to a suppressive effect of TNF on the HSC compartment, a recent study suggested that TNF increased the clonogenic potential of HSCs, elevated the number of multipotent progenitors (MPPs), and blocked cell death of HSCs by apoptosis [70]. Further, Pearl-Yafe et al. observed defects in early engraftment and a reduced competitive capacity of lineagenegative BM cells deficient for either TNFR1 or TNFR2 when transplanted into wild-type recipients [71]. In contrast, Pronk et al. observed a considerable competitive advantage of $T n f r 1^{--}$and $T n f r 2^{-/-}$(and even more pronounced $T$ nfr $1 / 2^{--}$) BM cells over wild-type BM when compared in a competitive transplantation setting. This phenotype was further enhanced after serial transplantation [72]. It therefore remains to be elucidated what the primary function of TNF on the HSC compartment is under physiological conditions.

Next to TNF, several alternative components of the necroptotic signaling machinery have been associated with HSC survival. For example, RIPK1 deletion in the hematopoietic compartment resulted in a severe cytokinemia and cell death that was partially rescued by co-deletion of RIPK3. The direct impact on the HSC compartment is illustrated by the finding that fetal liver cells from these mice failed to reconstitute lethally irradiated recipients $[73$, 
74]. Moreover, the functional CYLD-TRAF2 interaction protects HSC quiescence and dormancy by circumventing p38 MAPK activation and HSC cycling [75].

Demand-adapted granulopoiesis is controlled to a large degree by inflammatory signals released, at least in part, by necroinflammation. In an elegant study using gene-targeted mice, James Rickard et al. showed that RIPK1 represses an aberrant inflammatory response by inhibiting signal transduction via RIPK3 and MLKL in hematopoietic and nonhematopoietic cells [74].

In addition to TNF receptor signaling, TLR ligands also impact on the integrity of HSCs and thereby on their clonogenic potential. TLR4, TLR7, TLR8, and TLR9 are expressed on human $\mathrm{CD} 34^{+}$progenitor cells and stimulation of at least TLR7 and TLR8 in vitro resulted in myeloid differentiation of these cells [76]. Murine progenitors express TLR2 and TLR4, and TLR stimulation provoked HSPC cycling and enhanced myeloid differentiation [34, 77-80]. A more detailed overview of how inflammatory signals regulate HSCs is given in several recent reviews $[29,81,82]$.

In summary, these studies provide evidence that inflammatory signals influence HSCs to differentiate along specific hematopoietic lineages and hence directly impact on the output of mature blood cells into the periphery. Gene expression programs defining lineage decisions remain entangled over several early cell populations [83, 84]. Blood cells differentiate through the stage of MPPs that contribute to the steady-state maintenance of the blood cell pool $[85,86]$. The acute response to G-CSF represents a resource for the generation of substantial numbers of mature blood cells such as neutrophils originating likely from lineage-committed myeloid progenitors during emergency granulopoiesis [32, 33, 82, 87-89].

\section{Inflammation impacts on the homeostasis of HSCs}

Current data suggest that even in the absence of an active inflammation, inflammatory signals impact on HSC proliferation and thus on HSC numbers. Accordingly, even in healthy individuals some steady-state inflammatory signaling might influence the maintenance of a healthy HSPC compartment. In a murine model, this is exemplified by increased numbers of phenotypic hematopoietic progenitors at steady-state in TNFR1-deficient mice. The BM in these mice presents with an elevated cellularity in older mice, which goes hand in hand with a relative decrease in HSC functionality $[67,90]$. Accordingly, mice deficient for IFN $\gamma$, TLR4, TLR9, or MyD88 show elevated engraftment after lethal irradiation, likely because the HSC compartment in these mice remains in a more quiescent state due to the lack of inflammatory signals present at steady state [46, 91]. Also TLR signaling-deficient HSCs might be less vulnerable to the damaged/inflamed context of the lethally irradiated recipients, both preventing HSC cycling and ultimately exhaustion.

\section{The role of inflammatory signals for the development of HSC}

A range of different reports have shown that proinflammatory mediators impact on HSC biology during embryonic development [92-96]. The early development of the blood system proceeds in waves, where the development of HSCs follows the emergence of primitive erythroid and myeloid cells originating in the yolk sac. The emerging HSCs possess multi-lineage potential and themselves originate from hemogenic endothelial cells in the aorta-gonadmesonephros [97]. Interestingly, these early HSCs possess a typical inflammatory gene signature of innate immune cells with a particular IFN signature [93]. In addition to IFN, additional cytokines have been implicated in the development of HSCs including IL-1, -3, TNF, and G-CSF [94, 96, 98, 99]. The TNF/TNFR2 axis is involved in the correct development of embryonic HSCs [92, 95, 100] and the G-CSF/G-CSFR axis is required during embryonic emergency myelopoiesis and HSC emergence/expansion in embryonic development $[96,101]$. In an alternative study, both TNF and G-CSF promoted HSC development via TLR4 and MyD88 [95] and repression of TNF and IFN $\gamma$ resulted in HSC reduction, together supporting the notion that multiple proinflammatory cytokines possess cooperative roles in HSC development [93]. Based on these reports, the role of sterile inflammatory signaling seems to be of high relevance of the integrity of a functional HSC pool.

\section{Necroinflammation and BMF}

Although inflammatory signaling is critical during infection and inflammation, prolonged exposure to inflammatory signals including TLRs, IFNs, TNF, and IL-1 will repress the self-renewal of HSCs, which eventually results in HSC exhaustion [46, 51, 59, 60, 74, 102]. Indeed, myelodysplastic syndromes (MDSs) and BMF syndromes have been associated with excessive TNF and IFN $\gamma$ signaling, both of which have been proposed to contribute to the repression of hematopoietic cells [57, 61, 66, 103].

Several studies suggested an important role for necroptosis in the pathogenesis of BMF syndromes. Hematopoietic RIPK1 deficiency resulted in constitutive activation of RIPK3 and MLKL and induction of IFN $\gamma$-mediated RIPK3dependent necroptosis [73], culminating in elevated serum 
TNF and IFN $\gamma$ levels, HSPC loss, and ultimately BMF. In gene-targeted mice deficient for Takl, both apoptosis and necroptosis pathways impacted on the BM resulting in BMF and on HSC integrity as evidenced by RIPK1-dependent TNF-mediated cell death occurring in $30-40 \%$ of HSPCs. The remaining HSPCs in this model died by a Caspase-8dependent apoptotic route [104].

The functional relevance of individual cytokines in controlling the integrity of the hematopoietic system in the BM likely depends on several interacting factors that cannot be summarized easily into one simple equation. As discussed above this is illustrated in a model where TNF and IFN $\gamma$ exhibited opposing functions in acquired aplastic anemia, a condition defined by a loss of functional stem cell units unable to maintain relevant levels of mature blood cells. Here, IFN $\gamma$ repressed BM hematopoiesis in the wake of an autoimmune response, whereas TNF improved the BMF by blocking type-1 $\mathrm{T}$ lymphocyte responses and maintaining the function of myeloid-derived suppressor cells [105].

\section{Inflammation in ageing HSPCs}

Continuous proinflammatory signaling occurs also during aging in the BM environment. Typically, we can observe this in the BM of elderly patients that often present with a progressive anemia, senescence of immune cells, and reduced platelet numbers [106]. This is associated with elevated levels of the classic proinflammatory mediators including IL-1, IL-6, and TNF. Of note, IL- $1 \alpha$ released from senescent cells in the BM niche might be responsible for (i) triggering the secretion of those cytokines and (ii) the subsequent alterations in the BM (also termed "senescenceassociated secretory phenotype") [107, 108]. It is not difficult to speculate that this cocktail of cytokines present in the BM over extended periods of time will impact on HSC integrity and function.

Another curious aspect of age-related changes in the BM readily observed in elderly patients is the bias toward myeloid differentiation. This phenotype is characterized by the propensity of HSCs of elderly individuals to reconstitute more readily the myeloid system compared with the lymphoid lineage [109]. But not only HSCs themselves contribute to this myeloid skewing. The chemokine regulated on activation, normal $\mathrm{T}$ cell expressed and secreted (RANTES) released from aged BM niche cells was recently shown to contribute to HSC myeloid skewing [110]. The relatively high overlap of aged myeloid cells and myeloid leukemic progenitor cells in terms of their epigenetic and transcriptional profile suggests that this myeloid lineage bias might not be completely irrelevant in the elevated incidence of myeloid neoplasms present in the elderly population [111]. In line with this concept, younger leukemia patients mostly present with lymphoblastic leukemia when compared with the incidence of myeloid leukemia [112]. The notable exception of course is chronic lymphocytic leukemia (CLL).

Aging likely affects the integrity of the HSCs due to a low-level inflammatory condition over extended periods of time, which favors the development of pre-leukemic mutations [112, 113] and the progression of more aggressive sub-clones [114], which likely result in the development of overt myeloid leukemia (Fig. 3). Once a preleukemic subpopulation or a leukemia-initiating clone has developed in the BM environment, its close interaction with the surrounding niche cells will likely propagate the disease based on the presence of proinflammatory cytokines including IL-6, IL-8, IL-1 $\beta$, as well as danger signals such as S100A8/S100A9.

In summary, inflammatory cytokines likely contribute to aging-related hematological diseases, such as acute myeloid leukemia (AML), MDS, and myeloproliferative neoplasm (MPN), as all of those conditions are characterized by elevated levels of IFNs, TNF, and IL-6 [114-119].

\section{Necroptosis signaling in hematopoietic malignancies}

A range of hematopoietic cancers including chronic conditions, such as MDS, MPN (incl. CML), and CLL, but also more aggressive forms, such as AML, are characterized by alterations to proinflammatory signals. As eluded to before, both the microenvironment and the malignant clone itself contributes to the disease phenotype as inflammatory signaling originates from both cellular compartments. Alterations to the interplay between hematopoietic cells and the niche relevantly drives disease progression and the disease phenotype [119-123]. Of note, the crosstalk between niche cells and malignant clone can be multifaceted as individual inflammatory signals, such as IL-1 $\beta$ and TNF, can promote cellular differentiation of leukemic progenitor cells thereby effectively reducing self-renewal and survival of the malignant clone [124].

Over the last years, substantial interest has emerged in the crosstalk between the necroptotic pathway and hematopoietic malignancies. There is now considerable evidence showing that the expression of key players of the necroptosis signaling machinery can be disturbed in human cancers. In CLL, RIPK3 and CYLD expression are recurrently repressed by lymphoid enhancer-binding factor (LEF)1, a transcriptional repressor of CYLD [125]. Co-stimulation by TNF and zVAD could not induce necroptosis in CLL cells, but knockdown of LEF 1 re-sensitized CLL cells to TNF-induced necroptosis, 


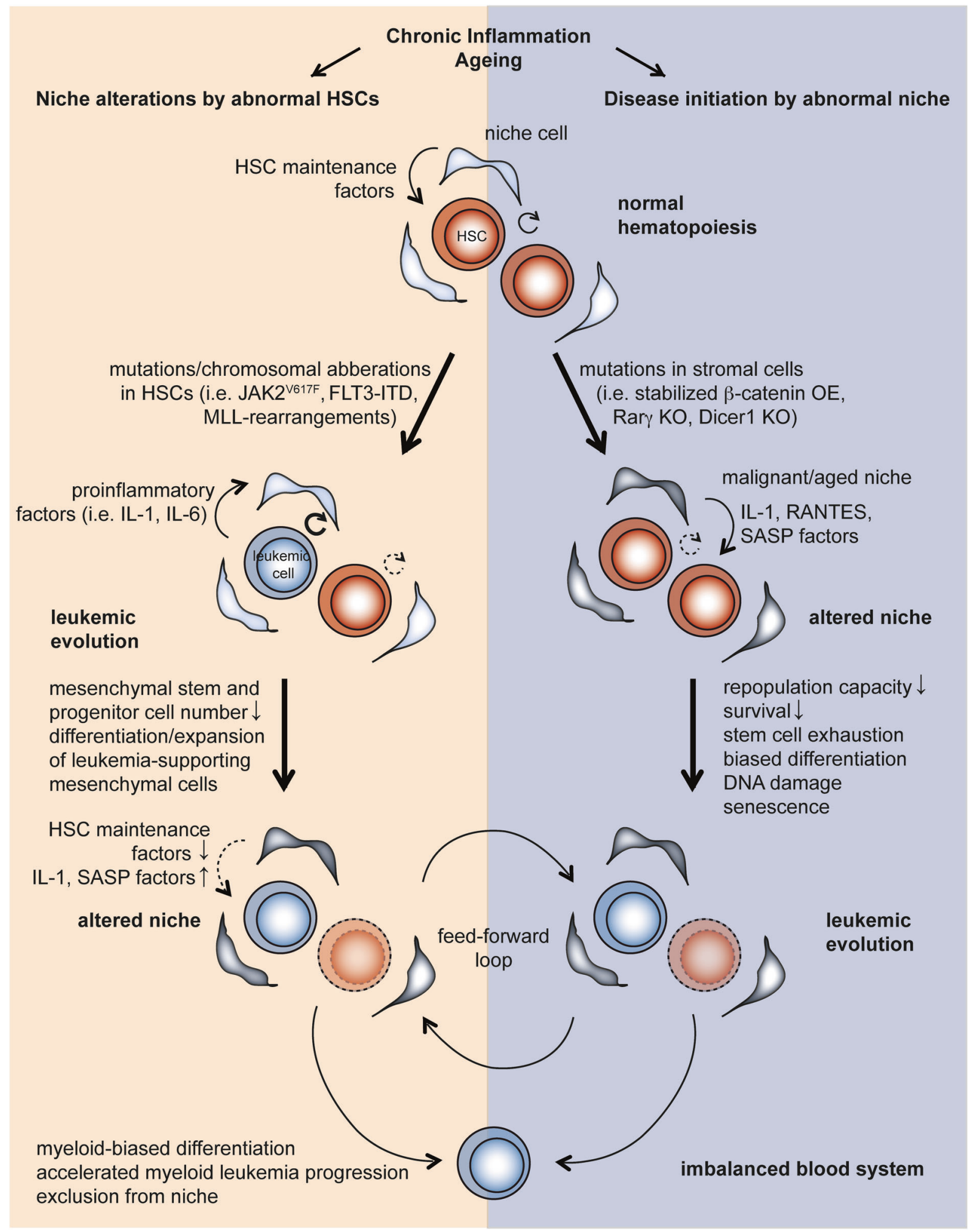

Fig. 3 Inflammatory factors released from leukemic cells influence the stromal compartment during leukemogenesis. Chronic inflammation and the natural ageing process are associated with a systemic overabundance of proinflammatory cytokines (middle panel), a phenotype absent under healthy steady-state conditions (upper panel). A chronic inflammatory state may contribute to the acquisition of genetic lesions in both HSCs and niche cells (middle panel). Eventually, leukemic cells induce changes in the HSC niche by the release of danger signals including chemokines, cytokines, and DAMPs (middle panel). The alterations of the niche by a malignant (pre)leukemic clone likely induces a self-reinforcing loop, contributing to disease progression (lower panel). KO knock-out, OE overexpression 
suggesting that the defect in necroptosis correlated with CLL pathogenesis [125]. Similar observations were made in lymphomas from $\mathrm{T}$-cell origin in which loss of RIPK3 signaling supported disease progression possibly as a result of necroptosis blockade [126]. Here, Caspase- 8 paradoxically promoted cell survival and also increased cellular growth by virtue of its protease activity [126]. Dissecting a cohort of 458 patients, an increased risk of development of non-Hodgkin lymphoma (NHL) was associated with single-nucleotide polymorphisms (SNPs) in RIPK3. This suggested that genetic aberrations of RIPK3 may contribute to the cancer development at least in NHL [127]. The most solid data set stems from work by the Quesnel and our lab that have recently shown that in several AML subtypes the expression of RIPK3 and $M L K L$, but not RIPK1, is reduced in patients $[124,128]$. In a cohort of over 70 primary patient samples, both mRNA and protein levels of RIPK3 are strongly reduced and, functionally, signaling via RIPK3 served as a tumor-suppressive mechanism in ((Fms Related Tyrosine Kinase 3) (FLT3)-(ITD) (internal tandem duplication)) and AML-ETO-driven AML [124]. The tumor-suppressive effect of RIPK3 signaling was dependent on (i) the induction of cell death in leukemiainitiating cells (LICs) and (ii) the propagation of myeloid differentiation induced by RIPK3-mediated IL- $1 \beta$ release further limiting leukemogenesis [124]. Notable exceptions were patients diagnosed with an AML characterized by mixed-lineage leukemia (MLL) translocations, which normally expressed RIPK3 and MLKL. Nugues et al. demonstrated that the expression of a RIPK3-kinase dead (KD) mutant in leukemia cells resulted in substantial early apoptosis that was antagonized by NF- $\mathrm{KB}$ activation [128].

\section{Necroinflammation and IL-1 in hematopoietic malignancies}

The interest of hematologists in IL-1 signaling has not subsided for many years. A recent spike in scientific interest in IL-1 signaling was fueled by studies on AML, in which its role remains, at least in part, controversial. Studies by Katsumura et al. and Carey et al. correlated elevated IL-1 expression in the BM of AML patients, which were mostly categorized as FAB M4 to M5, with an adverse outcome $[115,129]$. p38 MAPK-induced hyperphosphorylation of the transcription activator GATA2 increased expression of IL-1 $\beta$. In this report, IL-1 $\beta$ activated p38 MAPK thereby inducing a p38-GATA2-IL-1 $\beta$ feed forward loop [129]. This activation step further promoted the release of cytokines, chemokines, and growth factors [115]. These data stand in contrast to a study showing a 10-fold lower IL-1 expression in AML patients compared with healthy controls [130]. The different AML subtypes studied in these two publications might be partially responsible for the contradictory results: high IL-1 expression was found in FAB M4-M5 AML, whereas FAB M0-M2 AML showed low IL-1 expression [115, 129, 130]. Furthermore, CD34 ${ }^{+}$ and $\mathrm{CD} 38^{-}$AML progenitor cells downregulated the expression of IL-1 $\beta$ by epigenetic silencing, when compared with less primitive AML progenitor cell populations $\left(\mathrm{CD} 34^{+} \mathrm{CD} 38^{+}\right)$and even when compared with healthy $\mathrm{CD} 34^{+}$progenitors. Forced IL-1 $\beta$ expression inhibited selfrenewal, promoted cell cycle progression, and induced apoptotic cell death in $\mathrm{CD} 34^{+} \mathrm{CD} 38^{-}$AML progenitors. Even functionally, the hematopoietic engraftment and the capacity to reconstitute immunocompromised mice by these cells was reduced [131]. These findings are consistent with our observations that IL-1 $\beta$ induced LIC differentiation and prolonged leukemia onset in an AML mouse model driven by FLT3-ITD [124]. In contrast, Carey et al. provided evidence that $\mathrm{IL}-1$ receptor silencing resulted in a significant reduction of AML clonogenic potential and extended survival in an AML mouse model driven by AML1-ETO9a/Nras ${ }^{\text {G12D }}$ [115]. Furthermore, in MLLrearranged AML, MLL wild-type protein was degraded after IL-1-induced phosphorylation of the ubiquitin ligase ubiquitin-conjugating enzyme E2 O (UBE2O) [132]. Stabilization of wild-type MLL through interleukin-1 receptor-associated kinase inhibition impaired LSC function and prolonged leukemia onset in an MLL-AF9 mouse model of AML [132]. Together, these data show the differences in IL-1 expression and signaling in blasts and leukemic stem cells (Fig. 4).

\section{Induction of necroptosis as therapeutic option for hematopoietic malignancies}

Consistent across several hematopoietic cancers is the development of resistance to apoptosis. Thus, significant interest has emerged in recent years in the activation of necroptotic cell death as an alternative therapeutic strategy. Inhibitors of IAP proteins that resemble Second Mitochondria-Derived Activator Of Caspase (SMAC) (also termed DIABLO) are clinically speaking a relatively novel class of compounds that promote auto-ubiquitylation and proteasomal degradation of IAP proteins, thereby inducing TNF-mediated apoptosis $[133,134]$ or TNFmediated necroptosis [10]. The blockade and degradation of IAP proteins, including cIAP1, cIAP2 and/or XIAP, result in the activation of RIPK1 and RIPK3-mediated signaling events, which includes the autocrine production of TNF, and the promotion of cell death and expression of multiple cytokines and chemokines [134, 135]. Moreover, 
FLT3-ITD
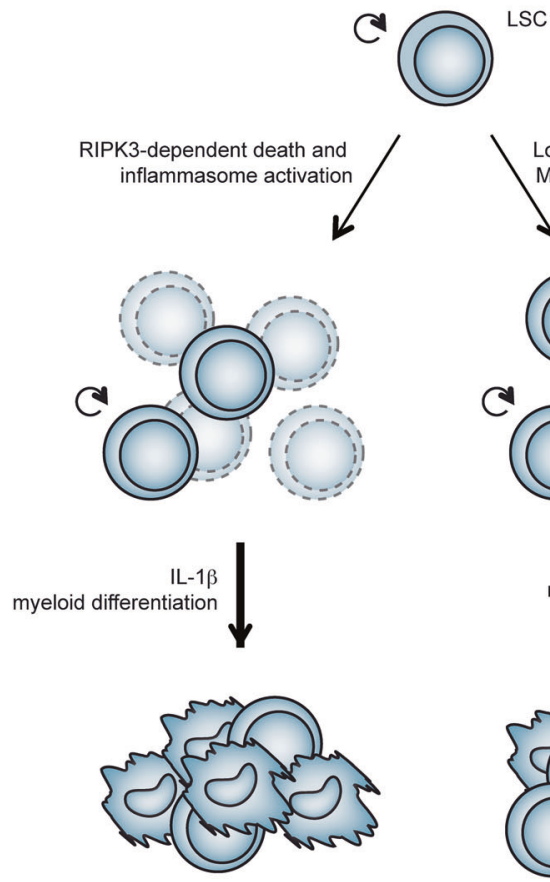

MPN
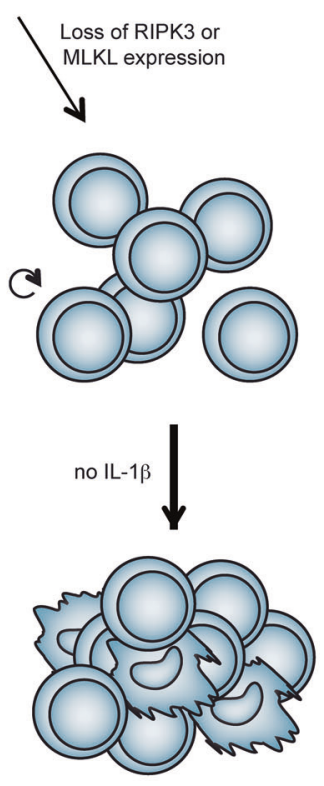

AML

Fig. 4 Leukemic blasts and LSCs regulate IL-1 expression and response to IL-1 differently-depending on the underlying genetic lesion. In FLT3-ITD-mutated leukemic stem cells (LSCs) that are proficient for RIPK3, TNFR signaling induced RIPK3-dependent cell death and inflammasome activation. The release of IL-1 $\beta$ by dying cells promoted differentiation of LSCs along the myeloid lineage, further limiting leukemogenesis to a non-transplantable MPN. Loss of either RIPK3 or MLKL severely blunted LIC death, IL- $1 \beta$ secretion, and myeloid differentiation resulting in an overt transplantable AML (left panel). In normal HSCs, IL- $1 \beta$ signaling through IL-1R1 drives UBE2O phosphorylation mediated by IRAK4. This increased UBE2O

IAP antagonists promote RIPK3-dependent inflammasomeor Caspase-8-mediated processing of IL-1 $\beta$ [25].

These observations provide evidence for the use of IAP antagonists for cell death induction as an unprecedented anti-neoplastic therapeutic avenue. In cell line models, the data supporting a relevant role of IAP antagonists against hematopoietic cancers was relatively positive. Several reports show that the IAP antagonist BV6 promoted elimination of ALL and AML cells as single agent or in combination with additional chemotherapeutics such as cytarabine or epigenetic modifiers (i.e., demethylating agents, histone deacetylase inhibitors), ionizing radiation, TRAIL, IFN $\alpha$, and others [136-142]. The therapeutic benefit of these IAP antagonists was placed on the possibility to induce cell death also in cell lines that were refractory to chemo- or radiotherapy. In clinical trials of cancer patients, the results were less promising and IAP antagonists have not provided clear evidence of a relevant therapeutic efficacy as single agent. Elucidating all aspects

MLL-rearrangements
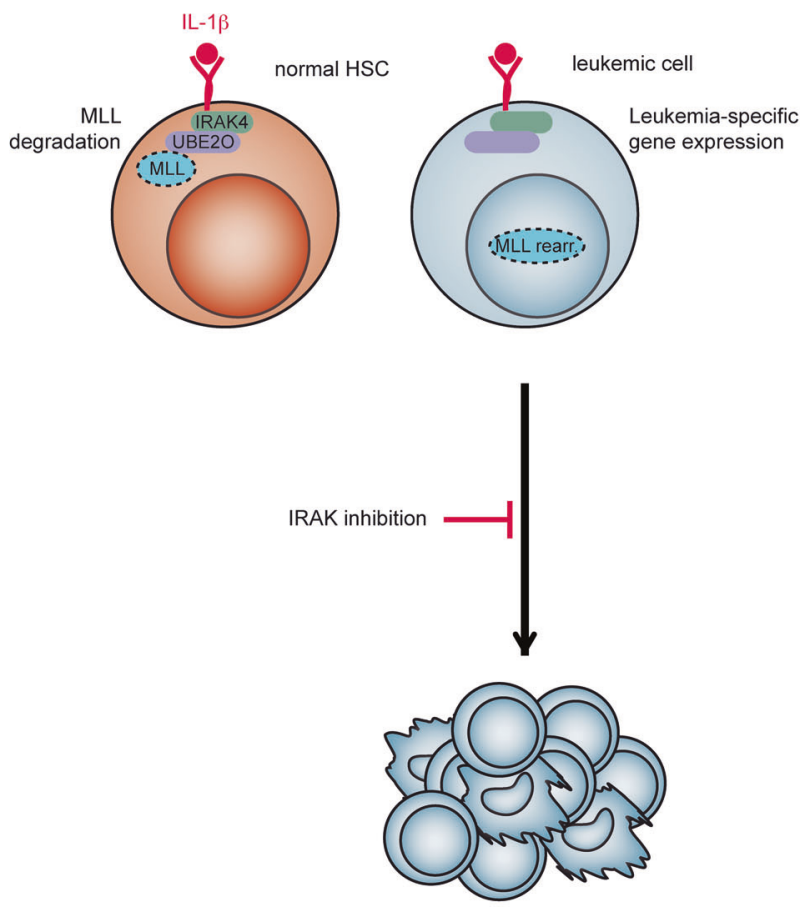

AML

interaction with MLL and its degradation (right panel). In contrast, in AML that results from expression of rearranged MLL fusion proteins, MLL chimeras are resistant to degradation driven by IL-1 $\beta$. IL-1 $\beta$ promoted leukemia cell proliferation and upregulated a specific group of MLL chimera target genes. Compounds blocking this signaling events considerably deferred leukemia progression by stabilizing wildtype MLL. This displaced the aberrant fusion of MLL from binding to several of its target sequences. Subsequently, wild-type MLL protected the cells from their addiction to MLL chimeras (see text for details). IRAK4 interleukin-1 receptor-associated kinase 4, UBE2O ubiquitinconjugating enzyme E2 O

of clinical trial data on IAP antagonists extends beyond the scope of this review, however, data reported by John Silke's lab provide evidence that certain AML subsets display specific sensitivities to the cIAP1/2-selective inhibitor Birinapant, depending on the oncogenic mutations present [143, 144]. Effective killing by necroptosis was obtained when Birinapant was given in combination with p38 inhibitors [144] or a Caspase-8-inhibitor [143]. Strikingly, Caspase- 8 inhibition showed remarkable synergy with Birinapant in vivo, and significantly increased survival of treated AML-burdened mice. Even Birinapant-resistant cells remained sensitive to the combination [143].

Furthermore, analysis of ALL patient samples of diverse subtypes identified subsets that were sensitive to Birinapant alone or in combination with vincristine, dexamethasone, and L-asparaginase $[145,146]$. Birinapant efficiently eliminated the ALL cells by inducing both RIPK1 kinasedependent apoptosis and necroptosis [145]. Together, these data support the notion that forced induction of necroptosis 
might hold therapeutic potential in hematopoietic cancers and potentially even in cases, which exhibit resistance to conventional chemotherapeutics. However, effective doses of necroptosis-inducing drugs and the biomarkers predicting responses will need to be determined.

\section{Is it beneficial to activate the RIPK1-RIPK3 signaling axis in all cancers?}

Depending on the cancer cell type and the tumor microenvironment, necroptosis can have a differential impact on tumor development and progression. For instance, in pancreatic ductal adenocarcinoma (PDA) the necrosome components RIPK1 and RIPK3 serve as tumor-promoting factors by eliciting a form of inflammation that supports tumor progression. RIPK3 deletion or pharmacologic RIPK1 blockade protected mice from PDA progression [147]. These data are curious but at least supported by immunohistochemistry data on RIPK3 protein expression levels in human PDA in our lab (unpublished observation), suggesting that signaling along the RIPK1-RIPK3 axis might harbor tumor-promoting activity.

On the other hand, necroptosis as a form of inflammation and as a cell death modality potentially also promotes antitumor immunity $[27,148]$. Vaccination using necroptotic cancer cells induced maturation of dendritic cells, cross-priming of $\mathrm{CD} 8 \mathrm{a}^{+} \mathrm{T}$ lymphocytes, and production of IFN $\gamma$, together promoting antitumor responses [148]. In the light of recent advances in immune check point inhibition, it is not difficult to speculate that boosting cell death by regulated necrosis might serve as a powerful tool to improve the anticancer immune responses elicited by anti-PD-1, anti-PD-L1, or anti-CTLA-4 antibodies. To date, it remains only partially understood which cancer types can be killed by inducing necroptosis (such as certain AML subtypes) and which cancer types likely utilize necrosomedependent inflammation to boost tumor progression.

\section{Concluding remarks/future perspectives}

Inflammation, in part as a result of regulated necrosis, is closely connected with the hematopoietic system, both as the regular outcome of mature blood cells and as a control mechanism defining stem cell fate. By now a wealth of data support the notion that inflammation holds the potential to directly impact on HSC integrity by (i) promoting normal development and functional integrity of HSCs under certain conditions, whereas (ii) inducing loss of HSC self-renewal and functional decline in others.

From a clinical perspective, several implications of necroinflammation are important. Proinflammatory cytokines critically regulate hematopoiesis, HSC function, hematopoietic progenitors, and the BM niche. In the case of cancer, this may shape the tumor microenvironment and promote survival and proliferation of neoplastic cells or, alternatively, it might promote cellular differentiation and cell death thereby repressing tumor development or progression [124]. Thus, understanding the interaction between (necro)inflammation and HSC biology may yield substantial advances in the treatment of hematological malignancies.

Despite extensive genomics-based analyses of the mutational landscape in AML and ALL, there has been only a limited number of novel treatment options implemented into current therapeutic regimens in these patients. This illustrates that it might be advisable to put more focus on the inflammatory circuits present in hematopoietic cancers and the $\mathrm{BM}$ environment. Understanding the molecular interaction between (necro)inflammation and HSC biology may therefore yield substantial new developments for the treatment of blood cancers.

Hematologists have been focusing on the rare leukemia stem cells (LSCs) (also termed LICs) that represent the reservoir for minimal residual disease detected in many leukemia patients even after aggressive polychemotherapy. Our inability to precisely understand their weaknesses in combination with the complex methodology needed to define, detect, and target these cells, has been a major stumbling block in our efforts to combat leukemia clinically. Utilizing forced induction of necroptosis or inflammatory signaling to target specific biologic processes of these LSCs such as their differentiation blockade or resistance to cell death might help to devise strategies to specifically eradicate both LSCs and blast cells. Improving our understanding of cell death and inflammation in the HSC compartment both at steady state, during conditions of emergency granulopoiesis and in malignancy might help to provide a rational how to boost inflammatory signaling pathways and providing death signals to achieve the demise of these LICs.

\section{Compliance with ethical standards}

Conflict of interest The authors declare that they have no conflict of interest.

\section{References}

1. Sarhan M, Land WG, Tonnus W, Hugo CP, Linkermann A. Origin and consequences of necroinflammation. Physiol Rev. 2018;98:727-80.

2. Kaczmarek A, Vandenabeele P, Krysko DV. Necroptosis: the release of damage-associated molecular patterns and its physiological relevance. Immunity. 2013;38:209-23.

3. Mulay SR, Linkermann A, Anders HJ. Necroinflammation in kidney disease. J Am Soc Nephrol. 2016;27:27-39. 
4. Croker BA, Silke J, Gerlic M. Fight or flight: regulation of emergency hematopoiesis by pyroptosis and necroptosis. Curr Opin Hematol. 2015;22:293-301.

5. Holler N, Zaru R, Micheau O, Thome M, Attinger A, Valitutti S, et al. Fas triggers an alternative, caspase-8-independent cell death pathway using the kinase RIP as effector molecule. Nat Immunol. 2000;1:489-95.

6. Thapa RJ, Nogusa S, Chen P, Maki JL, Lerro A, Andrake M, et al. Interferon-induced RIP1/RIP3-mediated necrosis requires PKR and is licensed by FADD and caspases. Proc Natl Acad Sci USA. 2013;110:E3109-18.

7. He S, Liang Y, Shao F, Wang X. Toll-like receptors activate programmed necrosis in macrophages through a receptorinteracting kinase-3-mediated pathway. Proc Natl Acad Sci USA. 2011;108:20054-9.

8. Upton JW, Kaiser WJ, Mocarski ES. Virus inhibition of RIP3dependent necrosis. Cell Host Microbe. 2010;7:302-13.

9. Vanden Berghe T, Linkermann A, Jouan-Lanhouet S, Walczak H, Vandenabeele P. Regulated necrosis: the expanding network of non-apoptotic cell death pathways. Nat Rev Mol Cell Biol. 2014;15:135-47.

10. Micheau O, Tschopp J. Induction of TNF receptor I-mediated apoptosis via two sequential signaling complexes. Cell. 2003; 114:181-90.

11. Walczak H. Death receptor-ligand systems in cancer, cell death, and inflammation. Cold Spring Harb Perspect Biol. 2013;5: a008698.

12. Grootjans S, Vanden Berghe T, Vandenabeele P. Initiation and execution mechanisms of necroptosis: an overview. Cell Death Differ. 2017;24:1184-95.

13. Cai Z, Jitkaew S, Zhao J, Chiang HC, Choksi S, Liu J, et al. Plasma membrane translocation of trimerized MLKL protein is required for TNF-induced necroptosis. Nat Cell Biol. 2014;16: $55-65$.

14. Keusekotten K, Elliott PR, Glockner L, Fiil BK, Damgaard RB, Kulathu Y, et al. OTULIN antagonizes LUBAC signaling by specifically hydrolyzing Met1-linked polyubiquitin. Cell. 2013; 153:1312-26.

15. de Almagro MC, Goncharov T, Newton K, Vucic D. Cellular IAP proteins and LUBAC differentially regulate necrosomeassociated RIP1 ubiquitination. Cell Death Dis. 2015;6: e1800.

16. Najjar M, Saleh D, Zelic M, Nogusa S, Shah S, Tai A, et al. RIPK1 and RIPK3 kinases promote cell-death-independent inflammation by Toll-like receptor 4. Immunity. 2016;45: $46-59$.

17. Hitomi J, Christofferson DE, Ng A, Yao J, Degterev A, Xavier RJ, et al. Identification of a molecular signaling network that regulates a cellular necrotic cell death pathway. Cell. 2008;135:1311-23.

18. Biton S, Ashkenazi. ANEMO and RIP1 control cell fate in response to extensive DNA damage via TNF-alpha feed forward signaling. Cell. 2011;145:92-103.

19. Christofferson DE, Li Y, Hitomi J, Zhou W, Upperman C, $\mathrm{Zhu} \mathrm{H}$, et al. A novel role for RIP1 kinase in mediating TNF alpha production. Cell Death Dis. 2012;3:e320.

20. Moriwaki K, Chan FK. Necrosis-dependent and independent signaling of the RIP kinases in inflammation. Cytokine Growth Factor Rev. 2014;25:167-74.

21. Yabal M, Muller N, Adler H, Knies N, Gross CJ, Damgaard RB, et al. XIAP restricts TNF- and RIP3-dependent cell death and inflammasome activation. Cell Rep. 2014;7:1796-808.

22. Lawlor KE, Khan N, Mildenhall A, Gerlic M, Croker BA, D'Cruz AA, et al. RIPK3 promotes cell death and NLRP3 inflammasome activation in the absence of MLKL. Nat Commun. 2015;6:6282.
23. Moriwaki K, Bertin J, Gough PJ, Chan FK. A RIPK3-caspase 8 complex mediates atypical pro-IL-1beta processing. J Immunol. 2015;194:1938-44.

24. Moriwaki K, Balaji S, McQuade T, Malhotra N, Kang J, Chan FK. The necroptosis adaptor RIPK3 promotes injury-induced cytokine expression and tissue repair. Immunity. 2014;41:567-78.

25. Vince JE, Wong WW, Gentle I, Lawlor KE, Allam R, O'Reilly L, et al. Inhibitor of apoptosis proteins limit RIP3 kinase-dependent interleukin-1 activation. Immunity. 2012;36: 215-27.

26. Wong WW, Vince JE, Lalaoui N, Lawlor KE, Chau D, Bankovacki A, et al. cIAPs and XIAP regulate myelopoiesis through cytokine production in an RIPK1- and RIPK3-dependent manner. Blood. 2014;123:2562-72.

27. Yatim N, Jusforgues-Saklani H, Orozco S, Schulz O, Barreira da Silva R, Reis e Sousa C, et al. RIPK1 and NF-kappaB signaling in dying cells determines cross-priming of $\operatorname{CD} 8(+) \mathrm{T}$ cells. Science. 2015;350:328-34.

28. Medzhitov R. Origin and physiological roles of inflammation. Nature. 2008;454:428-35.

29. Baldridge MT, King KY, Goodell MA. Inflammatory signals regulate hematopoietic stem cells. Trends Immunol. 2011;32:57-65.

30. King KY, Goodell MA. Inflammatory modulation of HSCs: viewing the HSC as a foundation for the immune response. Nat Rev Immunol. 2011;11:685-92.

31. Manz MG, Boettcher S. Emergency granulopoiesis. Nat Rev Immunol. 2014;14:302.

32. Haas S, Hansson J, Klimmeck D, Loeffler D, Velten L, Uckelmann $\mathrm{H}$, et al. Inflammation-induced emergency megakaryopoiesis driven by hematopoietic stem cell-like megakaryocyte progenitors. Cell Stem Cell. 2015;17:422-34.

33. Pietras EM, Reynaud D, Kang YA, Carlin D, Calero-Nieto FJ, Leavitt AD, et al. Functionally distinct subsets of lineage-biased multipotent progenitors control blood production in normal and regenerative conditions. Cell Stem Cell. 2015;17:35-46.

34. Zhao JL, Ma C, O'Connell RM, Mehta A, DiLoreto R, Heath JR, et al. Conversion of danger signals into cytokine signals by hematopoietic stem and progenitor cells for regulation of stressinduced hematopoiesis. Cell Stem Cell. 2014;14:445-59.

35. Young K, Borikar S, Bell R, Kuffler L, Philip V, Trowbridge JJ. Progressive alterations in multipotent hematopoietic progenitors underlie lymphoid cell loss in aging. J Exp Med. 2016;213:2259-67.

36. Pietras EM, Warr MR, Passegue E. Cell cycle regulation in hematopoietic stem cells. J Cell Biol. 2011;195:709-20.

37. Yu VW, Scadden DT. Heterogeneity of the bone marrow niche. Curr Opin Hematol. 2016;23:331-8.

38. Asada N, Takeishi S, Frenette PS. Complexity of bone marrow hematopoietic stem cell niche. Int J Hematol. 2017;106:45-54.

39. England H, Summersgill HR, Edye ME, Rothwell NJ, Brough D. Release of interleukin-1alpha or interleukin-1beta depends on mechanism of cell death. J Biol Chem. 2014;289:15942-50.

40. Gross O, Yazdi AS, Thomas CJ, Masin M, Heinz LX, Guarda G, et al. Inflammasome activators induce interleukin-1alpha secretion via distinct pathways with differential requirement for the protease function of caspase-1. Immunity. 2012;36:388-400

41. Bergsbaken T, Fink SL, Cookson BT. Pyroptosis: host cell death and inflammation. Nat Rev Microbiol. 2009;7:99-109.

42. Schuettpelz LG, Borgerding JN, Christopher MJ, Gopalan PK, Romine MP, Herman AC, et al. G-CSF regulates hematopoietic stem cell activity, in part, through activation of Toll-like receptor signaling. Leukemia. 2014;28:1851-60.

43. Liu F, Poursine-Laurent J, Wu HY, Link DC. Interleukin-6 and the granulocyte colony-stimulating factor receptor are major independent regulators of granulopoiesis in vivo but are not required for lineage commitment or terminal differentiation. Blood. 1997;90:2583-90. 
44. Zhang P, Iwama A, Datta MW, Darlington GJ, Link DC, Tenen DG. Upregulation of interleukin 6 and granulocyte colony-stimulating factor receptors by transcription factor CCAAT enhancer binding protein alpha (C/EBP alpha) is critical for granulopoiesis. J Exp Med. 1998;188:1173-84.

45. Masters SL, Gerlic M, Metcalf D, Preston S, Pellegrini M, O'Donnell JA, et al. NLRP1 inflammasome activation induces pyroptosis of hematopoietic progenitor cells. Immunity. 2012;37: 1009-23.

46. Baldridge MT, King KY, Boles NC, Weksberg DC, Goodell MA. Quiescent haematopoietic stem cells are activated by IFN-gamma in response to chronic infection. Nature. 2010;465:793-7.

47. Kim J, Kim W, Le HT, Moon UJ, Tran VG, Kim HJ, et al. IL-33-induced hematopoietic stem and progenitor cell mobilization depends upon CCR2. J Immunol. 2014;193:3792-802.

48. Dyer KD, Percopo CM, Rosenberg HF. IL-33 promotes eosinophilia in vivo and antagonizes IL-5-dependent eosinophil hematopoiesis ex vivo. Immunol Lett. 2013;150:41-7.

49. Ben Baruch-Morgenstern N, Shik D, Moshkovits I, Itan M, Karo-Atar D, Bouffi C, et al. Paired immunoglobulin-like receptor $\mathrm{A}$ is an intrinsic, self-limiting suppressor of IL-5induced eosinophil development. Nat Immunol. 2014;15:36-44.

50. Huang Y, Guo L, Qiu J, Chen X, Hu-Li J, Siebenlist U, et al. IL-25-responsive, lineage-negative KLRG1(hi) cells are multipotential 'inflammatory' type 2 innate lymphoid cells. Nat Immunol. 2015;16:161-9.

51. Essers MA, Offner S, Blanco-Bose WE, Waibler Z, Kalinke U, Duchosal MA, et al. IFNalpha activates dormant haematopoietic stem cells in vivo. Nature. 2009;458:904-8.

52. Platanias LC. Mechanisms of type-I- and type-II-interferonmediated signalling. Nat Rev Immunol. 2005;5:375-86.

53. Sato $T$, Onai $N$, Yoshihara $H$, Arai $F$, Suda $T$, Ohteki $T$. Interferon regulatory factor- 2 protects quiescent hematopoietic stem cells from type Iinterferon-dependent exhaustion. Nat Med. 2009;15:696.

54. Passegue E, Wagers AJ, Giuriato S, Anderson WC, Weissman IL. Global analysis of proliferation and cell cycle gene expression in the regulation of hematopoietic stem and progenitor cell fates. J Exp Med. 2005;202:1599-611.

55. Snoeck HW. Interferon gamma selectively inhibits very primitive CD342 + CD38- and not more mature CD34 + CD38+ human hematopoietic progenitor cells. J Exp Med. 1994;180: 1177-82.

56. Yang L, Dybedal I, Bryder D, Nilsson L, Sitnicka E, Sasaki Y, et al. IFN-negatively modulates self-renewal of repopulating human hemopoietic stem cells. J Immunol. 2005;174:752-7.

57. Zeng W, Miyazato A, Chen G, Kajigaya S, Young NS, Maciejewski JP. Interferon-gamma-induced gene expression in CD34 cells: identification of pathologic cytokine-specific signature profiles. Blood. 2006;107:167-75.

58. Selleri C, Sato T, Anderson S, Young NS, Maciejewski JP. Interferon-gamma and tumor necrosis factor-alpha suppress both early and late stages of hematopoiesis and induce programmed cell death. J Cell Physiol. 1995;165:538-46.

59. Matatall KA, Jeong M, Chen S, Sun D, Chen F, Mo Q, et al. Chronic infection depletes hematopoietic stem cells through stress-induced terminal differentiation. Cell Rep. 2016;17: 2584-95.

60. Matatall KA, Shen CC, Challen GA, King KY. Type II interferon promotes differentiation of myeloid-biased hematopoietic stem cells. Stem Cells. 2014;32:3023-30.

61. Young NS, Scheinberg P, Calado RT. Aplastic anemia. Curr Opin Hematol. 2008;15:162-8.

62. Lin FC, Karwan M, Saleh B, Hodge DL, Chan T, Boelte KC, et al. IFN-gamma causes aplastic anemia by altering hematopoietic stem/progenitor cell composition and disrupting lineage differentiation. Blood. 2014;124:3699-708.

63. Belyaev NN, Brown DE, Diaz AI, Rae A, Jarra W, Thompson J, et al. Induction of an IL7-R(+)c-Kit(hi) myelolymphoid progenitor critically dependent on IFN-gamma signaling during acute malaria. Nat Immunol. 2010;11:477-85.

64. Broxmeyer HE, Williams DE, Lu L, Cooper S, Anderson SL, Beyer GS, et al. The suppressive influences of human tumor necrosis factors on bone marrow hematopoietic progenitor cells from normal donors and patients with leukemia: synergism of tumor necrosis factor and interferon-gamma. J Immunol. 1986;136:4487-95.

65. Rusten LS, Jacobsen FW, Lesslauer W, Loetscher H, Smeland EB, Jacobsen SE. Bifunctional effects of tumor necrosis factor alpha (TNF alpha) on the growth of mature and primitive human hematopoietic progenitor cells: involvement of p55 and p75 TNF receptors. Blood. 1994;83:3152-9.

66. Dybedal I, Bryder D, Fossum A, Rusten LS, Jacobsen SE. Tumor necrosis factor (TNF)-mediated activation of the p55 TNF receptor negatively regulates maintenance of cycling reconstituting human hematopoietic stem cells. Blood. 2001;98: 1782-91.

67. Zhang Y, Harada A, Bluethmann H, Wang JB, Nakao S, Mukaida N, et al. Tumor necrosis factor (TNF) is a physiologic regulator of hematopoietic progenitor cells: increase of early hematopoietic progenitor cells in TNF receptor p55-deficient mice in vivo and potent inhibition of progenitor cell proliferation by TNF alpha in vitro. Blood. 1995;86:2930-7.

68. Jacobsen FW, Rothe M, Rusten L, Goeddel DV, Smeland EB, Veiby OP, et al. Role of the $75-\mathrm{kDa}$ tumor necrosis factor receptor: inhibition of early hematopoiesis. Proc Natl Acad Sci USA. 1994;91:10695-9.

69. Jacobsen SE, Ruscetti FW, Dubois CM, Keller JR. Tumor necrosis factor alpha directly and indirectly regulates hematopoietic progenitor cell proliferation: role of colony-stimulating factor receptor modulation. J Exp Med. 1992;175:1759-72.

70. Rezzoug F, Huang Y, Tanner MK, Wysoczynski M, Schanie CL, Chilton PM, et al. TNF- is critical to facilitate hemopoietic stem cell engraftment and function. J Immunol. 2007;180:49-57.

71. Pearl-Yafe M, Mizrahi K, Stein J, Yolcu ES, Kaplan O, Shirwan $\mathrm{H}$, et al. Tumor necrosis factor receptors support murine hematopoietic progenitor function in the early stages of engraftment. Stem Cells. 2010;28:1270-80.

72. Pronk CJ, Veiby OP, Bryder D, Jacobsen SE. Tumor necrosis factor restricts hematopoietic stem cell activity in mice: involvement of two distinct receptors. J Exp Med. 2011;208: 1563-70.

73. Roderick JE, Hermance N, Zelic M, Simmons MJ, Polykratis A, Pasparakis M, et al. Hematopoietic RIPK1 deficiency results in bone marrow failure caused by apoptosis and RIPK3-mediated necroptosis. Proc Natl Acad Sci USA. 2014;111:14436-41.

74. Rickard JA, O'Donnell JA, Evans JM, Lalaoui N, Poh AR, Rogers T, et al. RIPK1 regulates RIPK3-MLKL-driven systemic inflammation and emergency hematopoiesis. Cell. 2014;157: $1175-88$.

75. Tesio M, Tang Y, Mudder K, Saini M, von Paleske L, Macintyre E, et al. Hematopoietic stem cell quiescence and function are controlled by the CYLD-TRAF2-p38 MAPK pathway. J Exp Med. 2015;212:525-38.

76. Sioud M, Floisand Y, Forfang L, Lund-Johansen F. Signaling through toll-like receptor $7 / 8$ induces the differentiation of human bone marrow CD34 + progenitor cells along the myeloid lineage. J Mol Biol. 2006;364:945-54.

77. Nagai Y, Garrett KP, Ohta S, Bahrun U, Kouro T, Akira S, et al. Toll-like receptors on hematopoietic progenitor cells stimulate innate immune system replenishment. Immunity. 2006;24:801-12. 
78. Esplin BL, Shimazu T, Welner RS, Garrett KP, Nie L, Zhang Q, et al. Chronic exposure to a TLR ligand injures hematopoietic stem cells. J Immunol. 2011;186:5367-75.

79. Rodriguez S, Chora A, Goumnerov B, Mumaw C, Goebel WS, Fernandez L, et al. Dysfunctional expansion of hematopoietic stem cells and block of myeloid differentiation in lethal sepsis. Blood. 2009;114:4064-76.

80. Takizawa H, Regoes RR, Boddupalli CS, Bonhoeffer S, Manz MG. Dynamic variation in cycling of hematopoietic stem cells in steady state and inflammation. J Exp Med. 2011;208:273-84.

81. Clapes T, Lefkopoulos S, Trompouki E. Stress and non-stress roles of inflammatory signals during HSC emergence and maintenance. Front Immunol. 2016;7:487

82. Pietras EM. Inflammation: a key regulator of hematopoietic stem cell fate in health and disease. Blood. 2017;130:1693-8.

83. Laurenti E, Doulatov S, Zandi S, Plumb I, Chen J, April C, et al. The transcriptional architecture of early human hematopoiesis identifies multilevel control of lymphoid commitment. Nat Immunol. 2013;14:756-63.

84. Wilson NK, Kent DG, Buettner F, Shehata M, Macaulay IC, Calero-Nieto FJ, et al. Combined single-cell functional and gene expression analysis resolves heterogeneity within stem cell populations. Cell Stem Cell. 2015;16:712-24.

85. Busch K, Klapproth K, Barile M, Flossdorf M, Holland-Letz T, Schlenner SM, et al. Fundamental properties of unperturbed haematopoiesis from stem cells in vivo. Nature. 2015;518:542-6.

86. Sun J, Ramos A, Chapman B, Johnnidis JB, Le L, Ho YJ, et al. Clonal dynamics of native haematopoiesis. Nature. 2014;514: 322-7.

87. Cabezas-Wallscheid N, Klimmeck D, Hansson J, Lipka DB, Reyes A, Wang Q, et al. Identification of regulatory networks in HSCs and their immediate progeny via integrated proteome, transcriptome, and DNA methylome analysis. Cell Stem Cell. 2014:15:507-22.

88. Notta F, Zandi S, Takayama N, Dobson S, Gan OI, Wilson G, et al. Distinct routes of lineage development reshape the human blood hierarchy across ontogeny. Science. 2016;351:aab2116.

89. Yamamoto R, Morita Y, Ooehara J, Hamanaka S, Onodera M, Rudolph KL, et al. Clonal analysis unveils self-renewing lineagerestricted progenitors generated directly from hematopoietic stem cells. Cell. 2013;154:1112-26.

90. Rebel VI, Hartnett S, Hill GR, Lazo-Kallanian SB, Ferrara JL, Sieff CA. Essential role for the p55 tumor necrosis factor receptor in regulating hematopoiesis at a stem cell level. J Exp Med. 1999;190:1493-504.

91. Ichii M, Shimazu T, Welner RS, Garrett KP, Zhang Q, Esplin $\mathrm{BL}$, et al. Functional diversity of stem and progenitor cells with B-lymphopoietic potential. Immunol Rev. 2010;237:10-21.

92. Espin-Palazon R, Stachura DL, Campbell CA, Garcia-Moreno D, Del Cid N, Kim AD, et al. Proinflammatory signaling regulates hematopoietic stem cell emergence. Cell. 2014;159:1070-85.

93. Li Y, Esain V, Teng L, Xu J, Kwan W, Frost IM, et al. Inflammatory signaling regulates embryonic hematopoietic stem and progenitor cell production. Genes Dev. 2014;28:2597-612.

94. Sawamiphak S, Kontarakis Z, Stainier DY. Interferon gamma signaling positively regulates hematopoietic stem cell emergence. Dev Cell. 2014;31:640-53.

95. He Q, Zhang C, Wang L, Zhang P, Ma D, Lv J, et al. Inflammatory signaling regulates hematopoietic stem and progenitor cell emergence in vertebrates. Blood. 2015;125:1098-106.

96. Stachura DL, Svoboda O, Campbell CA, Espin-Palazon R, Lau $\mathrm{RP}$, Zon LI, et al. The zebrafish granulocyte colony-stimulating factors (Gcsfs): 2 paralogous cytokines and their roles in hematopoietic development and maintenance. Blood. 2013;122:3918-28.

97. De La Garza A, Sinha A, Bowman TV. Concise review: hematopoietic stem cell origins: lessons from embryogenesis for improving regenerative medicine. Stem Cells Transl Med. 2017;6:60-7.

98. Orelio C, Haak E, Peeters M, Dzierzak E. Interleukin-1-mediated hematopoietic cell regulation in the aorta-gonad-mesonephros region of the mouse embryo. Blood. 2008;112:4895-904.

99. Robin C, Ottersbach K, Durand C, Peeters M, Vanes L, Tybulewicz V, et al. An unexpected role for IL-3 in the embryonic development of hematopoietic stem cells. Dev Cell. 2006;11:171-80.

100. Kim AD, Melick CH, Clements WK, Stachura DL, Distel M, Panakova D, et al. Discrete Notch signaling requirements in the specification of hematopoietic stem cells. EMBO J. 2014; 33:2363-73.

101. Liongue C, Hall CJ, O'Connell BA, Crosier P, Ward AC. Zebrafish granulocyte colony-stimulating factor receptor signaling promotes myelopoiesis and myeloid cell migration. Blood. 2009;113:2535-46.

102. Pietras EM, Mirantes-Barbeito C, Fong S, Loeffler D, Kovtonyuk LV, Zhang S, et al. Chronic interleukin-1 exposure drives haematopoietic stem cells towards precocious myeloid differentiation at the expense of self-renewal. Nat Cell Biol. 2016;18:607-18.

103. Chen Y, Zou Z, Wu Z, Zhao Z, Luo X, Xie C, et al. TNF-alphainduced programmed cell death in the pathogenesis of acquired aplastic anemia. Expert Rev Hematol. 2015;8:515-26.

104. Xiao Y, Li H, Zhang J, Volk A, Zhang S, Wei W, et al. TNFalpha/Fas-RIP-1-induced cell death signaling separates murine hematopoietic stem cells/progenitors into 2 distinct populations. Blood. 2011;118:6057-67.

105. Xin J, Breslin P, Wei W, Li J, Gutierrez R, Cannova J, et al. Necroptosis in spontaneously-mutated hematopoietic cells induces autoimmune bone marrow failure in mice. Haematologica. 2017;102:295-307.

106. Denkinger MD, Leins H, Schirmbeck R, Florian MC, Geiger H. HSC aging and senescent immune remodeling. Trends Immunol. 2015;36:815-24.

107. Coppe JP, Desprez PY, Krtolica A, Campisi J. The senescenceassociated secretory phenotype: the dark side of tumor suppression. Annu Rev Pathol. 2010;5:99-118.

108. Orjalo AV, Bhaumik D, Gengler BK, Scott GK, Campisi J. Cell surface-bound IL-1alpha is an upstream regulator of the senescence-associated IL-6/IL-8 cytokine network. Proc Natl Acad Sci USA. 2009;106:17031-6.

109. Akunuru S, Geiger H. Aging, clonality, and rejuvenation of hematopoietic stem cells. Trends Mol Med. 2016;22: 701-12.

110. Ergen AV, Boles NC, Goodell MA. Rantes/Ccl5 influences hematopoietic stem cell subtypes and causes myeloid skewing. Blood. 2012;119:2500-9.

111. Beerman I, Bock C, Garrison BS, Smith ZD, Gu H, Meissner A, et al. Proliferation-dependent alterations of the DNA methylation landscape underlie hematopoietic stem cell aging. Cell Stem Cell. 2013;12:413-25.

112. Zambetti NA, Ping Z, Chen S, Kenswil KJG, Mylona MA, Sanders MA, et al. Mesenchymal inflammation drives genotoxic stress in hematopoietic stem cells and predicts disease evolution in human pre-leukemia. Cell Stem Cell. 2016;19: 613-27.

113. Chen L, Chen W, Mysliwski M, Serio J, Ropa J, Abulwerdi FA, et al. Mutated Ptpn11 alters leukemic stem cell frequency and reduces the sensitivity of acute myeloid leukemia cells to Mcl1 inhibition. Leukemia. 2015;29:1290-300.

114. Schepers K, Pietras EM, Reynaud D, Flach J, Binnewies M, Garg T, et al. Myeloproliferative neoplasia remodels the endosteal bone marrow niche into a self-reinforcing leukemic niche. Cell Stem Cell. 2013;13:285-99. 
115. Carey A, DKt Edwards, Eide CA, Newell L, Traer E, Medeiros $\mathrm{BC}$, et al. Identification of interleukin-1 by functional screening as a key mediator of cellular expansion and disease progression in acute myeloid leukemia. Cell Rep. 2017;18:3204-18.

116. Welner RS, Amabile G, Bararia D, Czibere A, Yang H, Zhang H, et al. Treatment of chronic myelogenous leukemia by blocking cytokine alterations found in normal stem and progenitor cells. Cancer Cell. 2015;27:671-81.

117. Ganan-Gomez I, Wei Y, Starczynowski DT, Colla S, Yang H, Cabrero-Calvo $M$, et al. Deregulation of innate immune and inflammatory signaling in myelodysplastic syndromes. Leukemia. 2015;29:1458-69.

118. Reynaud D, Pietras E, Barry-Holson K, Mir A, Binnewies M, Jeanne M, et al. IL-6 controls leukemic multipotent progenitor cell fate and contributes to chronic myelogenous leukemia development. Cancer Cell. 2011;20:661-73.

119. Korn C, Mendez-Ferrer S. Myeloid malignancies and the microenvironment. Blood. 2017;129:811-22.

120. Rozovski U, Keating MJ, Estrov Z. Targeting inflammatory pathways in chronic lymphocytic leukemia. Crit Rev Oncol Hematol. 2013;88:655-66.

121. Schepers K, Campbell TB, Passegue E. Normal and leukemic stem cell niches: insights and therapeutic opportunities. Cell Stem Cell. 2015;16:254-67.

122. Caligaris-Cappio F. Inflammation, the microenvironment and chronic lymphocytic leukemia. Haematologica. 2011;96: 353-5.

123. Herault A, Binnewies M, Leong S, Calero-Nieto FJ, Zhang SY, Kang YA, et al. Myeloid progenitor cluster formation drives emergency and leukaemic myelopoiesis. Nature. 2017;544:53-8.

124. Höckendorf U, Yabal M, Herold T, Munkhbaatar E, Rott S, Jilg $S$, et al. RIPK3 restricts myeloid leukemogenesis by promoting cell death and differentiation of leukemia initiating cells. Cancer Cell. 2016;30:75-91.

125. Liu P, Xu B, Shen W, Zhu H, Wu W, Fu Y, et al. Dysregulation of TNF alpha-induced necroptotic signaling in chronic lymphocytic leukemia: suppression of CYLD gene by LEF1. Leukemia. 2012;26:1293-300.

126. Kikuchi M, Kuroki S, Kayama M, Sakaguchi S, Lee KK, Yonehara S. Protease activity of procaspase- 8 is essential for cell survival by inhibiting both apoptotic and nonapoptotic cell death dependent on receptor-interacting protein kinase 1 (RIP1) and RIP3. J Biol Chem. 2012;287:41165-73.

127. Cerhan JR, Ansell SM, Fredericksen ZS, Kay NE, Liebow M, Call TG, et al. Genetic variation in 1253 immune and inflammation genes and risk of non-Hodgkin lymphoma. Blood. 2007; 110:4455-63.

128. Nugues AL, El Bouazzati H, Hetuin D, Berthon C, Loyens A, Bertrand E, et al. RIP3 is downregulated in human myeloid leukemia cells and modulates apoptosis and caspase-mediated p65/RelA cleavage. Cell Death Dis. 2014;5:e1384.

129. Katsumura KR, Ong IM, DeVilbiss AW, Sanalkumar R, Bresnick EH. GATA factor-dependent positive-feedback circuit in acute myeloid leukemia cells. Cell Rep. 2016;16:2428-41.

130. Su SJ, Yeh YT, Su SH, Chang KL, Shyu HW, Chen KM, et al. Biochanin a promotes osteogenic but inhibits adipogenic differentiation: evidence with primary adipose-derived stem cells. Evid Based Complement Altern Med. 2013;2013:846039.

131. Yang J, Ikezoe $T$, Nishioka $C$, Nobumoto A, Yokoyama A. IL-1beta inhibits self-renewal capacity of dormant CD34 $(+) /$ CD38(-) acute myelogenous leukemia cells in vitro and in vivo. Int J Cancer. 2013;133:1967-81.
132. Liang K, Volk AG, Haug JS, Marshall SA, Woodfin AR, Bartom ET, et al. Therapeutic targeting of MLL degradation pathways in MLL-rearranged leukemia. Cell. 2017;168:59-72.

133. Petersen SL, Wang L, Yalcin-Chin A, Li L, Peyton M, Minna J, et al. Autocrine TNF alpha signaling renders human cancer cells susceptible to Smac-mimetic-induced apoptosis. Cancer Cell. 2007;12:445-56.

134. Vince JE, Wong WW, Khan N, Feltham R, Chau D, Ahmed AU, et al. IAP antagonists target cIAP1 to induce TNF alphadependent apoptosis. Cell. 2007;131:682-93.

135. Varfolomeev E, Blankenship JW, Wayson SM, Fedorova AV, Kayagaki N, Garg P, et al. IAP antagonists induce autoubiquitination of c-IAPs, NF-kappaB activation, and TNF alphadependent apoptosis. Cell. 2007;131:669-81.

136. Safferthal C, Rohde K, Fulda S. Therapeutic targeting of necroptosis by Smac mimetic bypasses apoptosis resistance in acute myeloid leukemia cells. Oncogene. 2017;36:1487-502.

137. Chromik J, Safferthal C, Serve H, Fulda S. Smac mimetic primes apoptosis-resistant acute myeloid leukaemia cells for cytarabineinduced cell death by triggering necroptosis. Cancer Lett. 2014; 344:101-9.

138. Steinhart L, Belz K, Fulda S. Smac mimetic and demethylating agents synergistically trigger cell death in acute myeloid leukemia cells and overcome apoptosis resistance by inducing necroptosis. Cell Death Dis. 2013;4:e802.

139. Steinwascher S, Nugues AL, Schoeneberger H, Fulda S. Identification of a novel synergistic induction of cell death by Smac mimetic and HDAC inhibitors in acute myeloid leukemia cells. Cancer Lett. 2015;366:32-43.

140. Gerges S, Rohde K, Fulda S. Cotreatment with Smac mimetics and demethylating agents induces both apoptotic and necroptotic cell death pathways in acute lymphoblastic leukemia cells. Cancer Lett. 2016;375:127-32.

141. Schenk B, Fulda S. Reactive oxygen species regulate Smac mimetic/TNF alpha-induced necroptotic signaling and cell death. Oncogene. 2015;34:5796-806.

142. Rohde K, Kleinesudeik L, Roesler S, Lowe O, Heidler J, Schroder K, et al. A Bak-dependent mitochondrial amplification step contributes to Smac mimetic/glucocorticoid-induced necroptosis. Cell Death Differ. 2017;24:83-97.

143. Brumatti G, Ma C, Lalaoui N, Nguyen NY, Navarro M, Tanzer MC, et al. The caspase- 8 inhibitor emricasan combines with the SMAC mimetic birinapant to induce necroptosis and treat acute myeloid leukemia. Sci Transl Med. 2016;8:339ra69.

144. Lalaoui N, Hanggi K, Brumatti G, Chau D, Nguyen NY, Vasilikos L, et al. Targeting p38 or MK2 enhances the anti-leukemic activity of Smac-mimetics. Cancer Cell. 2016;29:145-58.

145. McComb S, Aguade-Gorgorio J, Harder L, Marovca B, Cario G, Eckert $\mathrm{C}$, et al. Activation of concurrent apoptosis and necroptosis by SMAC mimetics for the treatment of refractory and relapsed ALL. Sci Transl Med. 2016;8:339ra70.

146. Richmond J, Robbins A, Evans K, Beck D, Kurmasheva RT, Billups CA, et al. Acute sensitivity of Ph-like acute lymphoblastic leukemia to the SMAC-mimetic birinapant. Cancer Res. 2016;76:4579-91.

147. Seifert L, Werba G, Tiwari S, Giao Ly NN, Alothman S, Alqunaibit $\mathrm{D}$, et al. The necrosome promotes pancreatic oncogenesis via CXCL1 and mincle-induced immune suppression. Nature. 2016;532:245-9.

148. Aaes TL, Kaczmarek A, Delvaeye T, De Craene B, De Koker S, Heyndrickx L, et al. Vaccination with necroptotic cancer cells induces efficient anti-tumor immunity. Cell Rep. 2016;15:274-87. 